Tema: Solidificação / Lingotamento

\title{
OTIMIZAÇÃO DA PRODUÇÃO DE AÇOS BAIXO CARBONO MICROLIGADOS NA ARCELORMITTAL TUBARAO*
}

\begin{abstract}
Carlos Alberto Perim ${ }^{1}$ Fabiano Almir Barbosa ${ }^{2}$

Resumo

José Carlos de Pontes Júnior ${ }^{3}$

Os aços baixo carbono microligados representam uma parcela significativa da produção de placas de aço na ArcelorMittal Tubarão e sua participação na produção total tem sido crescente ao longo dos últimos anos. Entretanto, grande parte da necessidade do mercado por este tipo de material se dá em larguras pequenas, o que inviabiliza a sua produção em equipamentos de grande escala, como é o caso da ArcelorMittal Tubarão. Neste trabalho será apresentado um resumo das ações tomadas na ArcelorMittal Tubarão visando viabilizar a produção deste tipo de aço em pequenas larguras, através do aumento de sua velocidade de lingotamento e análise constante da qualidade interna das placas. Uma vez consolidado o aumento de velocidade, com a consequente redução do tempo de lingotamento, foi possível reavaliar a aceitação de placas com menor largura e padronizar esta nova condição. Também, durante a execução deste trabalho, foram reavaliados os critérios de retirada de amostras para os ensaios de macro-ataque nos aços de baixo carbono e baixa liga.
\end{abstract}

Palavras-chave: Produtividade; Lingotamento contínuo; Placa de aço.

\section{PRODUCTIVITY INCREASING OF LOW CARBON MICROALLOYED STEELS AT ARCELORMITTAL TUBARÃO}

\begin{abstract}
Low carbon microalloyed steels represent a significant portion of the steel slabs produced at ArcelorMittal Tubarão and its participation in the total output has been increasing over the past years. However, most of the market requirement for this kind of material occurs in small widths, which limits the production in large-scale equipment, as in the case of ArcelorMittal Tubarão. In this paper it will be presented a summary of the actions taken at ArcelorMittal Tubarão in order to enable the production of this type of steel in small widths, such as increasing its casting speed followed by constant analysis of the internal quality of the slabs. Once consolidated the speed increasing, with the consequent reduction of the casting time, it was possible to re-evaluate the acceptance of slabs with smaller width and standardize this new condition. Moreover, during the execution of this study, it was re-evaluated the criteria for the macroetch tests at the low carbon low alloy steels.
\end{abstract}

Keywords: Productivity; Continuous casting; Steel slabs.

1 Engenheiro Metalurgista, membro da ABM, M. Sc., Engenheiro de Processo do Lingotamento Contínuo da ArcelorMittal Tubarão, Vitória, ES, Brasil.

2 Engenheiro Metalurgista, membro da ABM, M.Sc., Engenheiro de Controle de Qualidade da ArcelorMittal Tubarão, Vitória, ES, Brasil.

3 Engenheiro Metalurgista, Gerente da Área de Confiabilidade Produção de Placa da ArcelorMittal Tubarão, Vitória, ES, Brasil.

\footnotetext{
* Contribuição técnica ao $45^{\circ}$ Seminário de Aciaria - Internacional, 25 a 28 de maio de 2014,
} 


\section{INTRODUÇÃO}

Os aços baixo carbono microligados são também conhecidos pelas siglas HSLA (High Strength Low Alloy) ou ARBL (Aços de Alta Resistência e Baixa Liga). Nesta categoria, estão muitos dos aços conhecidos como API, destinados à produção de tubos.

$\mathrm{Na}$ AM Tubarão, os aços baixo carbono microligados são classificados em uma família de aço específica, chamada de família 22, que é caracterizada por apresentar teor de carbono visado entre $0,025 \%$ e $0,085 \%$ e por possuir também os elementos de liga $\mathrm{Ti}, \mathrm{V}$ e $\mathrm{Nb}$ em faixa, com um valor mínimo de 0,02\% para quaisquer destes elementos.

A utilização de níveis baixos de carbono associados aos microligantes $\mathrm{V}$, Ti e $\mathrm{Nb}$ proporcionaram ao longo dos anos uma melhora da soldabilidade e da tenacidade destes aços. Com a melhora da propriedade mecânica, foi possível obter economia significativa nos custos de alguns projetos, como ilustrado no caso da Figura 1 [1].

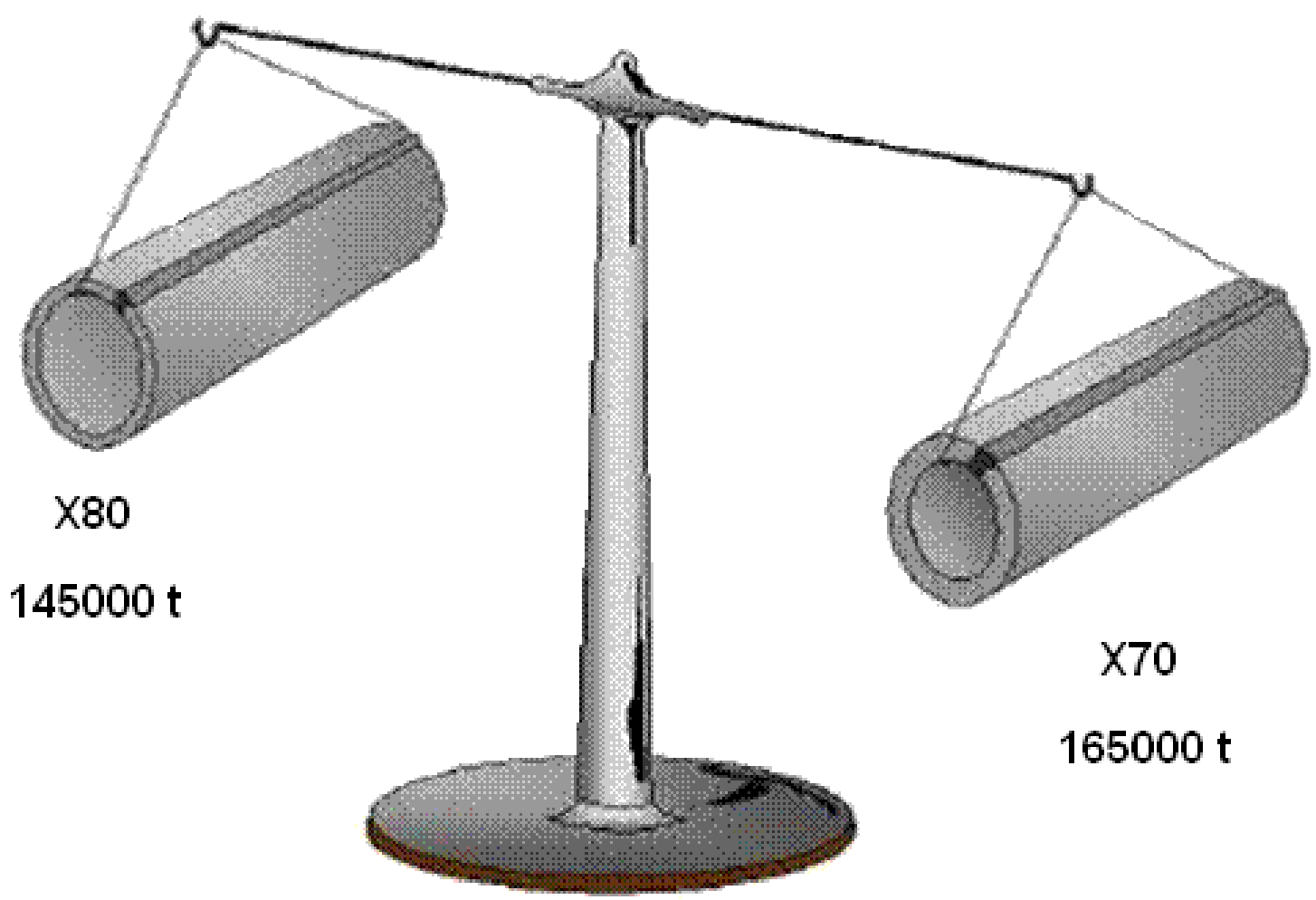

Figura 1. Economia de material no projeto X80 Ruhrgas.

Neste caso, o uso de aços API X80 conduziu a uma redução de peso de material de cerca de 20.000ton em relação à especificação $X 70$, obtida através da redução da espessura da parede do tubo de 20,8mm (X70) para 18,3mm (X80).

A evolução dos aços API tem sido obtida, entre outros fatores, pela redução do seu teor de carbono, conforme ilustrado na Figura 2 [2].

* Contribuição técnica ao $45^{\circ}$ Seminário de Aciaria - Internacional, 25 a 28 de maio de 2014, 

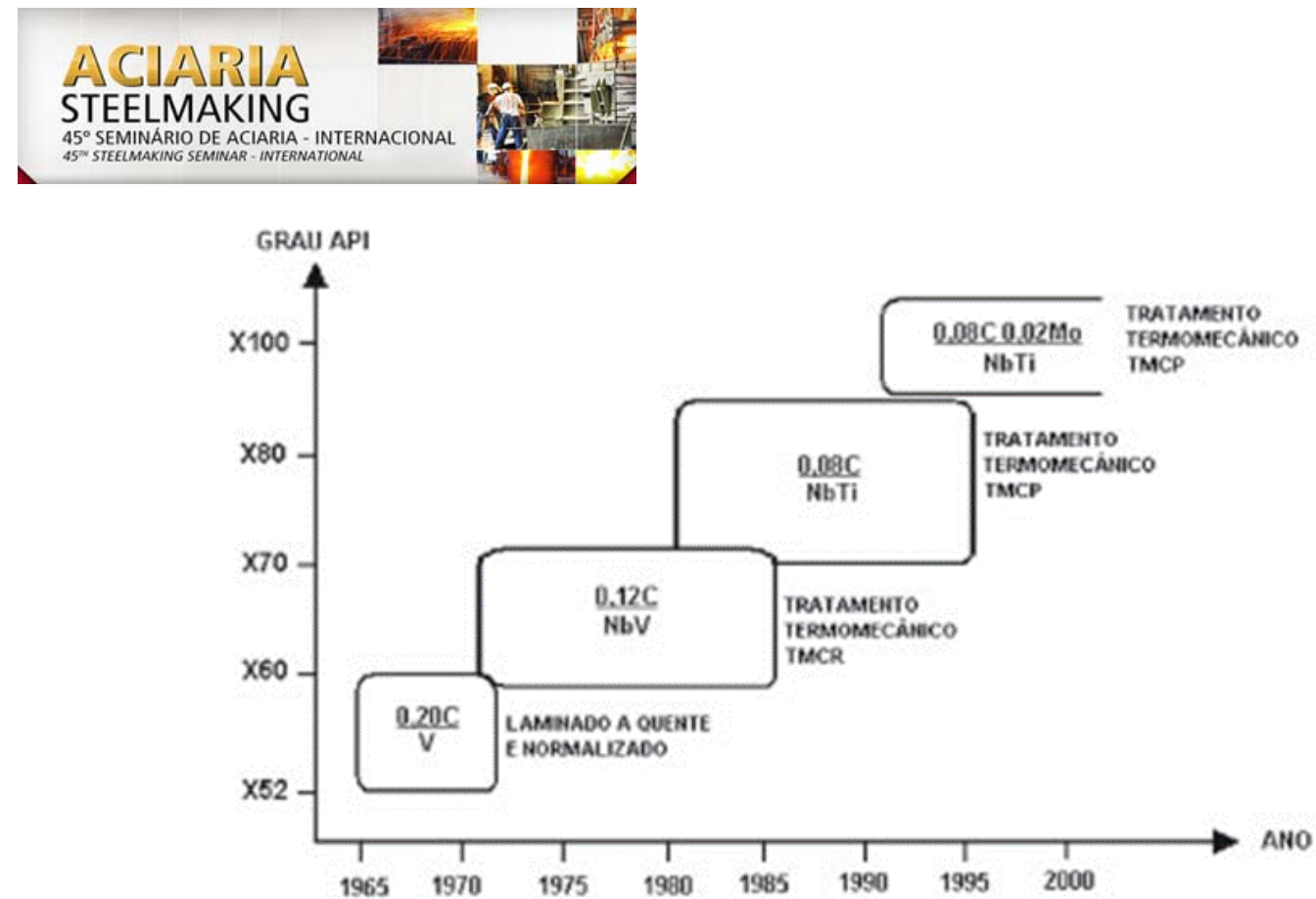

Figura 2. Evolução dos Aços API.

Com o contínuo aumento da produção de petróleo e gás no Brasil, também houve aumento da demanda por este tipo de material, representado na AM Tubarão, em parte, pela família de aço 22. Entretanto, grande parte dos aços requisitados não pôde ser aceita devido à pequena largura solicitada, que, por sua vez, resultava em baixo tempo médio de lingotamento.

Neste trabalho serão discutidas as ações que foram tomadas na ArcelorMittal Tubarão visando viabilizar a produção dos aços baixo carbono microligados em pequenas larguras, através do aumento de sua velocidade de lingotamento e análise constante da qualidade interna das placas.

Uma vez consolidado o aumento de velocidade, com a consequente redução do tempo de lingotamento, foi possível reavaliar a aceitação de placas com menor largura e padronizar esta nova condição. Também, durante a execução deste trabalho, foram reavaliados os critérios de retirada de amostras para a realização dos ensaios de macro-ataque nos aços de baixo carbono e baixa liga.

\section{MATERIAIS E MÉTODOS}

\subsection{Conceituando a Produtividade}

De forma geral, a produção total de uma máquina de lingotamento contínuo durante certo intervalo de tempo pode ser resumida pela seguinte expressão:

\section{Produção $=$ Produtividade $\mathbf{x}$ IT $\mathbf{x}$ Tempo Calendário}

Onde:

IT = Índice de trabalho (\% de tempo do equipamento operando)

Tempo calendário $=$ Tempo total do período considerado (ex: 1 ano)

Produtividade $=$ vazão de massa de aço em cada veio (média), em peso por unidade de tempo (ex: ton/min). Esta produtividade também é chamada de "throughput".

Por sua vez, a produtividade ("throughput") está relacionada às dimensões da placa e à densidade do aço que está sendo produzido pela seguinte expressão:

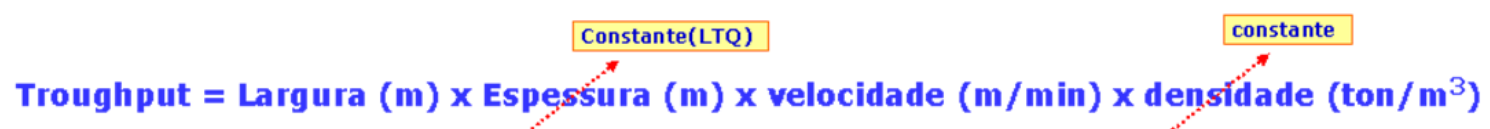

* Contribuição técnica ao 45 Seminário de Aciaria - Internacional, 25 a 28 de maio de 2014, 


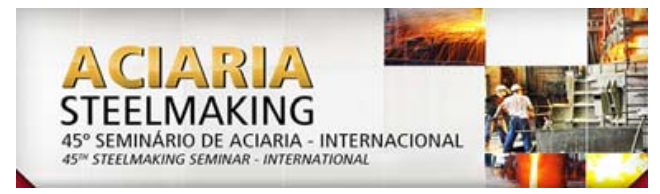

Como a espessura das placas destinadas ao LTQ é constante e a densidade do aço produzido varia muito pouco (aproximadamente constante), só se consegue aumento de produtividade com o aumento da velocidade de lingotamento ou da largura média da placa.

\subsection{Limites de Fabricação Dimensionais}

Os limites de fabricação na ArcelorMittal Tubarão estão ligados ao tempo de lingotamento. Acima de um determinado valor de tempo, as corridas não são aceitáveis, uma vez que ocorre perda de produtividade e risco de obstrução, devido à queda contínua de temperatura. O tempo de lingotamento é estimado pela seguinte expressão:

Tempo de lingotamento = Peso dé aço líquido (ton) $/$ Throughput $(x$ no de veios) $($ ton $/ \mathrm{min})(3)$

Na AM Tubarão, o peso médio de corrida é aproximadamente constante, por volta de 315 ton. Assim, existe um "throughput" mínimo aceitável para a produção, que, por sua vez, limita o aceite de materiais que tenham uma relação velocidade de lingotamento x largura não adequada.

Desta forma, realisticamente, para a produção de placas de menor largura, mantendo o tempo de lingotamento mínimo, é necessário aumentar a velocidade de lingotamento.

Assim, foi proposto neste trabalho o aumento da velocidade de lingotamento para os aços baixo carbono microligados (família de aço 22). A Figura 3 ilustra a mudança proposta na velocidade de lingotamento deste material na Máquina de Lingotamento Contínuo $N^{0} 1$ (MLC\#1), que foi executada em duas etapas. Vale ressaltar que esta alteração foi realizada também na Máquina de Lingotamento Contínuo No 2.

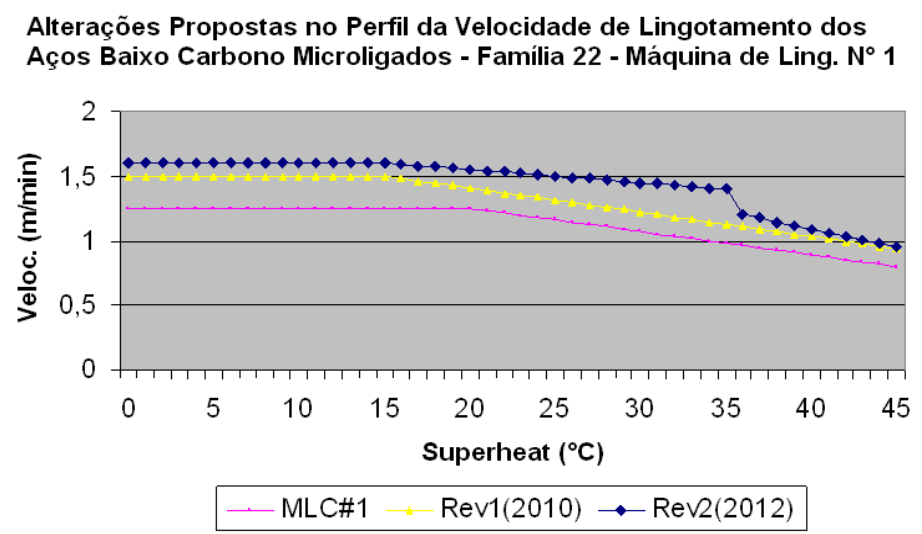

Figura 3. Proposta de aumento de velocidade de lingotamento para os aços baixo carbono microligados (família de aço 22) na MLC\#1.

\section{RESULTADOS}

O aumento de velocidade de lingotamento, que foi feito de forma progressiva e conforme proposta apresentada na Figura 3 permitiu que a largura média para se aceitar a produção destes aços fosse diminuída ao longo do projeto. Na Figura 4 se observa uma redução acima de $10 \%$ na largura média das placas produzidas no período de 2009 a 2013.

* Contribuição técnica ao $45^{\circ}$ Seminário de Aciaria - Internacional, 25 a 28 de maio de 2014, 


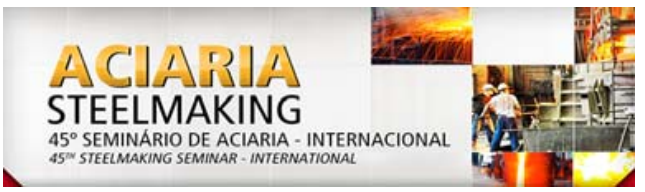

Evolução da Largura Média de Placa do Material Baixo Carbono Microligado - Fam. 22 - ArcelorMittal Tubarão

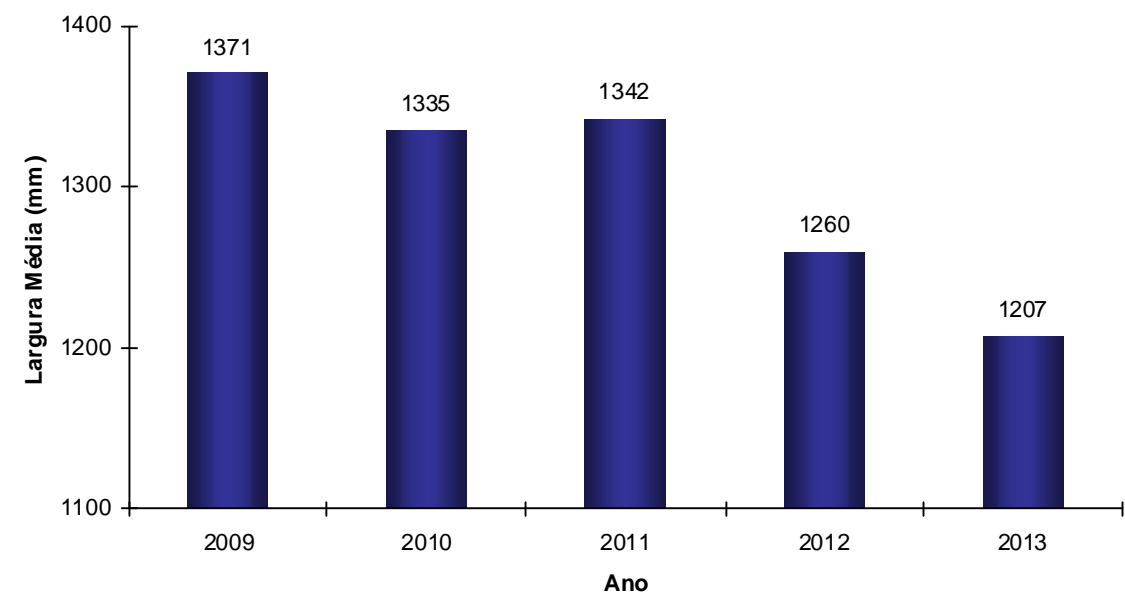

Figura 4. Evolução da largura média de placa dos aços baixo carbono microligados na AM Tubarão.

Para se aceitar larguras cada vez menores, a velocidade média de lingotamento subiu em proporção próxima à da queda de largura.

Evolução da Velocidade Média de Lingotamento no Material Baixo Carbono Microligado - Fam. 22 - ArcelorMittal Tubarão

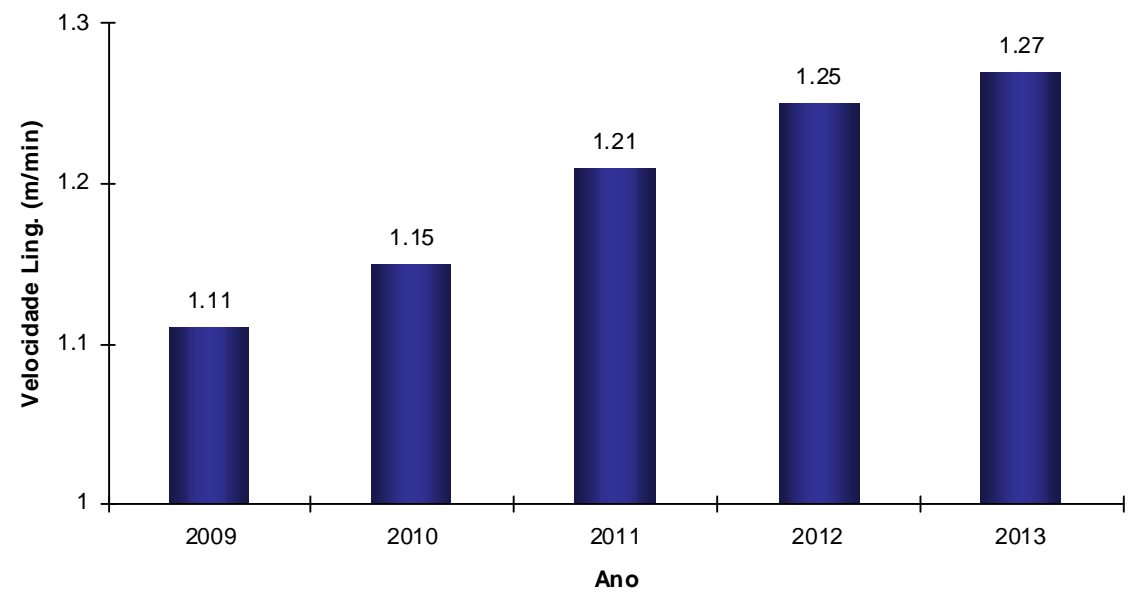

Figura 5. Aumento da velocidade média de lingotamento nos aços baixo carbono microligados na AM Tubarão.

Uma vez estabelecida esta nova condição para aceite de pedidos, o volume de aço baixo carbono produzido nas máquinas de lingotamento contínuo vem apresentando aumento contínuo. Em 2009 este volume foi de cerca de 147.000 ton, ao passo que, em 2013, considerando até meados do mês de novembro, este volume já representava cerca de 361.000 ton. A Figura 6 ilustra este crescimento em termos de participação no total de aço produzido na AMT.

* Contribuição técnica ao $45^{\circ}$ Seminário de Aciaria - Internacional, 25 a 28 de maio de 2014, Porto Alegre, RS, Brasil. 


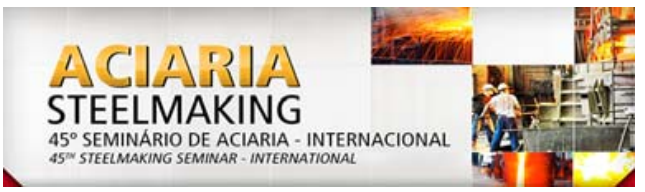

Evolução da Produção de Material Baixo Carbono Microligado Fam. 22 -ArcelorMittal Tubarão

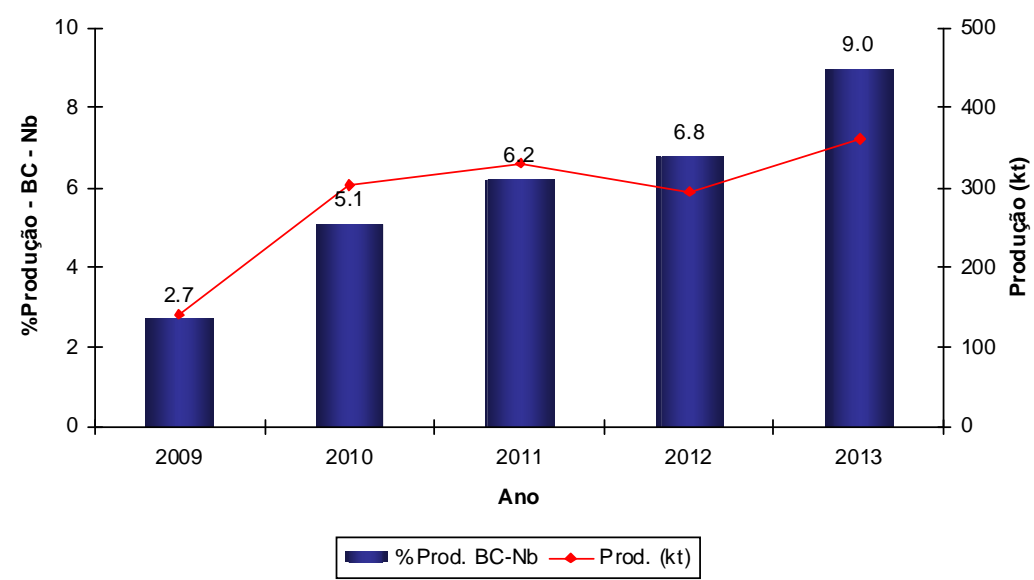

Figura 6. Participação dos aços baixo carbono microligados na produção total da AM Tubarão.

\section{DISCUSSÃO}

O aumento de velocidade poderia conduzir a um eventual aumento na formação de trincas internas, trincas superficiais transversais, ou mesmo, no aumento do número de inclusões e um consequente aumento no nível de esfoliação. Visando a acompanhar estes possíveis efeitos colaterais, foi feito um acompanhamento contínuo da qualidade das placas produzidas nesta nova condição de processo.

\subsection{Análise da Qualidade Interna das Placas - Trincas e Segregação Central}

Foram avaliados os dados referentes aos ensaios de macro-ataque no material baixo carbono microligado (família 22) no período de 2009 a 2013. Neste período, foram analisadas aproximadamente 3.500 amostras no laboratório de macro-ataque. $\mathrm{Na}$ ArcelorMittal Tubarão o padrão utilizado para classificar o ensaio de macroataque é o Mannesmann, com níveis de trinca e segregação central variando entre 1 e 5 e são aceitáveis níveis de defeito de no máximo 3.0 para o este material.

A Figura 7 apresenta os resultados de trincas internas transversais e longitudinais obtidos nas máquinas de lingotamento $\mathrm{N}^{0} 1$ e №2 em função da velocidade de lingotamento.
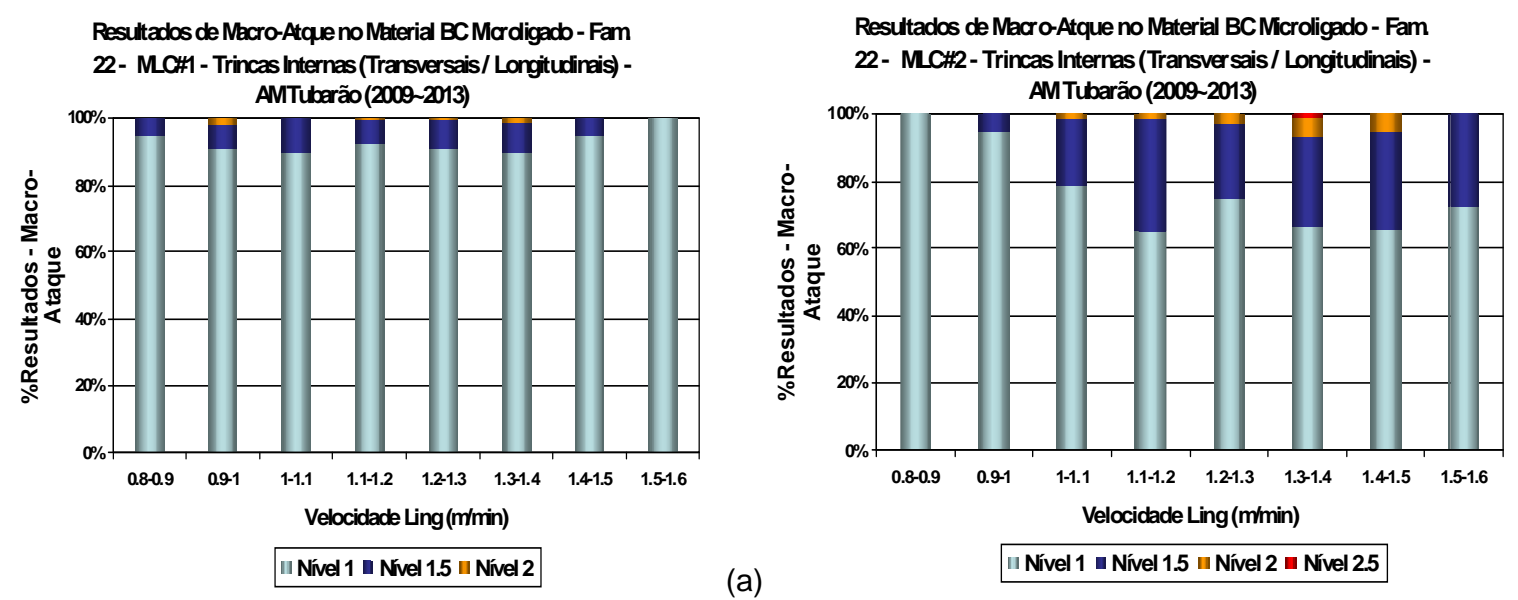

(a)

Figura 7. Resultados de macro-ataque - trincas internas transversais / longitudinais - em função da velocidade de lingotamento no material baixo carbono microligado a) MLC\#1; b) MLC\#2.

* Contribuição técnica ao $45^{\circ}$ Seminário de Aciaria - Internacional, 25 a 28 de maio de 2014, Porto Alegre, RS, Brasil. 
Na máquina de lingotamento $N^{0} 1$ (MLC\#1), que é uma máquina curva, os níveis de trinca se mostraram muito bons, mesmo em velocidades elevadas. Já na máquina de lingotamento $\mathrm{N}^{\circ} 2$ (MLC\#2), vertical-curva, os níveis de trinca apresentaram tendência de elevação com o aumento da velocidade de lingotamento. Contudo, a partir de uma velocidade de $1.1 \mathrm{~m} / \mathrm{min}$, os resultados de trinca se mostraram estáveis.

Como não houve ocorrências de trincas internas com níveis superiores ou iguais a 3.0 na escala Mannesmann (somente 01 ocorrência com nível 2.5), a prática de elevação da velocidade de lingotamento no material baixo carbono microligado não deteriorou significativamente a qualidade interna das placas nas MLC\#1 e MLC\#2.

A Figura 8 apresenta os resultados de segregação central obtidos nas máquinas de lingotamento $\mathrm{N}^{0} 1$ e No2 em função da velocidade de lingotamento.
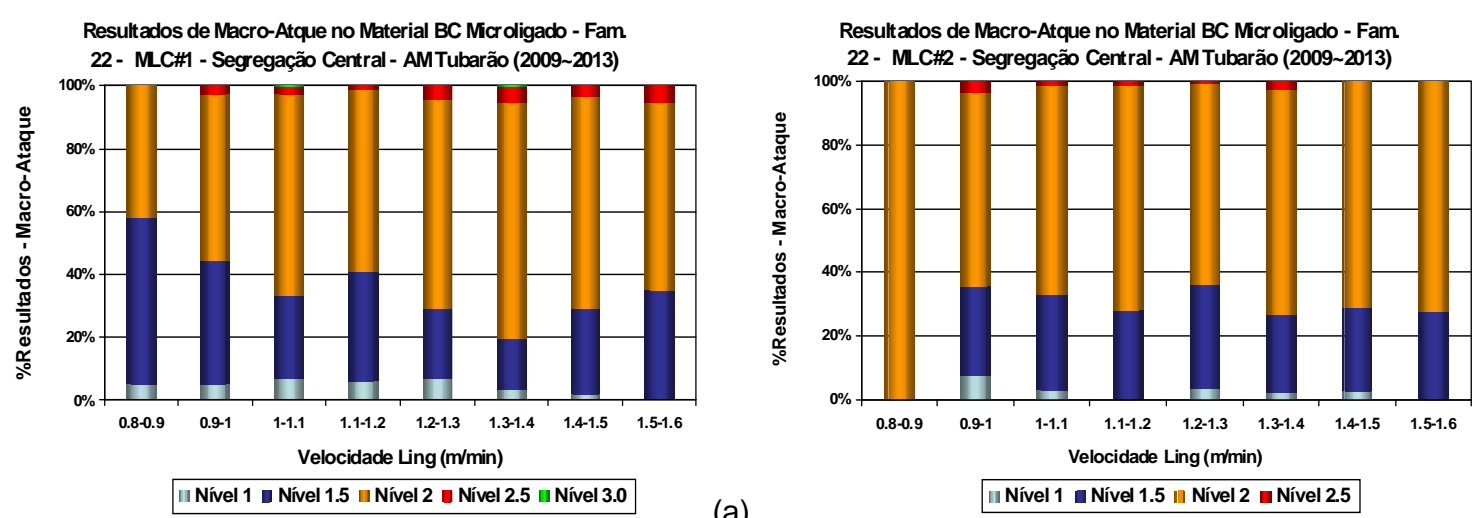

(a)

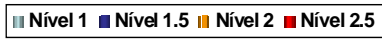

(b)

Figura 8. Resultados de macro-ataque - segregação central - em função da velocidade de lingotamento no material baixo carbono microligado a) MLC\#1; b) MLC\#2.

Na máquina de lingotamento $N^{0} 1$ (MLC\#1), os níveis de segregação central apresentaram leve tendência de elevação com o aumento da velocidade de lingotamento, mas sem ocorrências de níveis de segregação superiores a 3.0. Já na máquina de lingotamento $\mathrm{N}^{\circ} 2$ (MLC\#2), os níveis de segregação central foram muito bons e não sofreram influências do aumento da velocidade.

Os resultados de segregação central também confirmaram que o aumento da velocidade de lingotamento no material baixo carbono microligado não impactou negativamente na qualidade interna das placas nas MLC\#1 e MLC\#2.

A Figura 9 apresenta um resultado típico de macro-ataque para o material baixo carbono microligado lingotado em alta velocidade $(1,5 \mathrm{~m} / \mathrm{min})$.

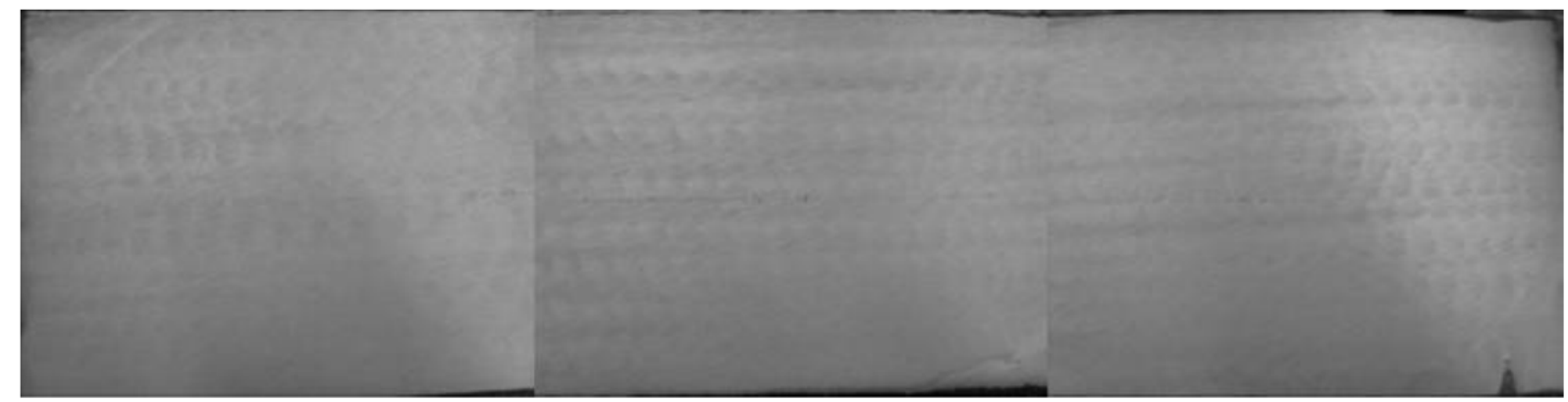

Figura 9. Resultado de macro-ataque em amostra transversal retirada em placa de material baixo carbono microligado lingotado em alta velocidade $-1.5 \mathrm{~m} / \mathrm{min}$.

* Contribuição técnica ao 45 Seminário de Aciaria - Internacional, 25 a 28 de maio de 2014, Porto Alegre, RS, Brasil. 


\subsection{Avaliação da Qualidade Superficial - Ocorrência do Defeito Esfoliação em Material Laminado a Quente}

A esfoliação, também conhecida como "sliver", é um defeito superficial linear que ocorre na tira de aço. Este defeito ocorre paralelo ao sentido de laminação e pode surgir em qualquer lado, face e aleatório ao longo da largura e do comprimento da tira.

Embora seja um defeito com origem predominante no processo de refino do aço e de lingotamento contínuo, também pode ter origem nos processos de condicionamento e de laminação.

Diz-se que a esfoliação tem natureza química, quando atribuída ao processo de produção do aço na aciaria, e natureza mecânica, quando atribuída ao processo de condicionamento da placa ou ao processo de laminação.

Neste trabalho, avaliou-se o impacto do aumento da velocidade de lingotamento nos aços baixo carbono microligados sobre as desclassificações de bobinas por esfoliação no laminador de tiras a quente da ArcelorMittal Tubarão. A Figura 10 apresenta os índices de desclassificação e descarte de bobinas por esfoliação em função da velocidade de lingotamento.
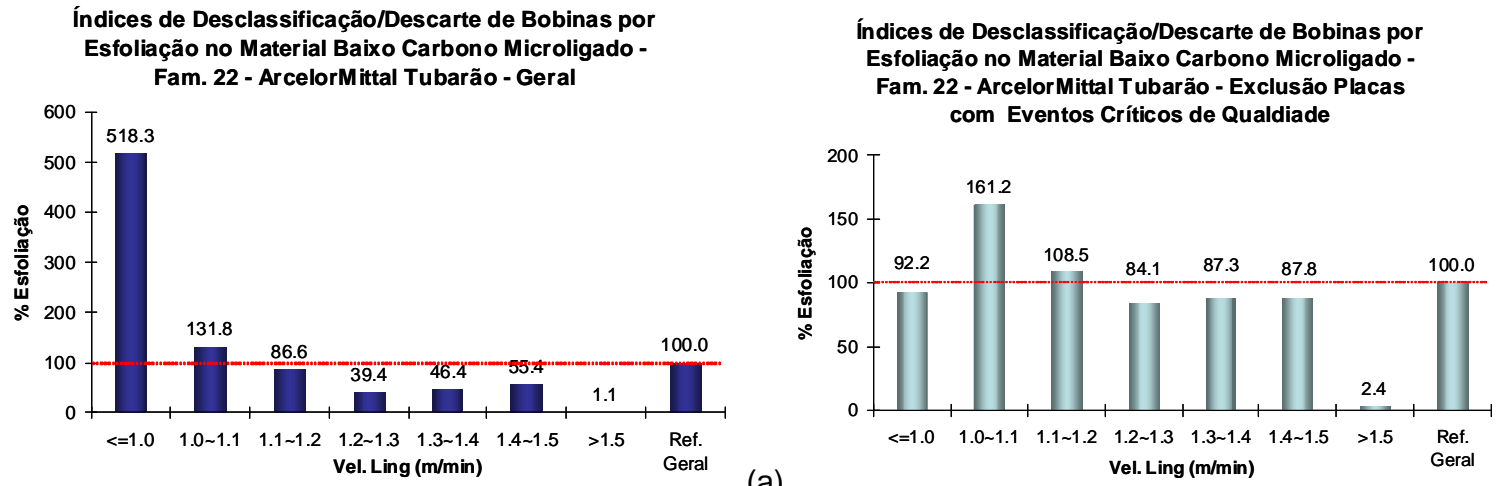

(a)

Vel. Ling ( $\mathrm{m} / \mathrm{min})$

(b)

Figura 10. Índices de desclassificação e de descarte de bobinas por esfoliação no laminador de tiras a quente da AM Tubarão em função da velocidade de lingotamento a) Geral - todas as placas; b) Exclusão de placas com eventos críticos de qualidade.

Verifica-se, com base na Figura 10, uma redução significativa dos índices de desclassificação e de descarte de bobinas por esfoliação quando se eleva a velocidade de lingotamento. Vale ressaltar que esta redução também foi observada nas placas que não apresentaram eventos críticos de qualidade, ou seja, em placas que não tiveram ocorrências de anormalidades operacionais durante o processo de lingotamento contínuo.

Assim, a prática de elevação da velocidade de lingotamento no material baixo carbono microligado proporcionou uma melhoria na qualidade superficial da placa e, consequentemente, acarretou em reduções dos índices de desclassificação e de descarte de bobinas por esfoliação na AM Tubarão.

\section{CONCLUSÃO}

Na ArcelorMittal Tubarão houve um aumento contínuo da demanda por aços baixo carbono microligados, a partir de 2009. Esta demanda se concentrava em aços de menor largura, que não poderiam ser fabricados nas condições de processo

* Contribuição técnica ao 45 Seminário de Aciaria - Internacional, 25 a 28 de maio de 2014, 


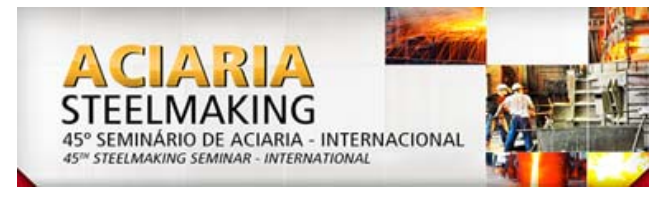

estabelecidas na época devido à baixa produtividade e longo tempo de lingotamento.

Através de uma avaliação dos limites de fabricação, ficou estabelecido que somente o aumento de velocidade de lingotamento permitiria aceitar a produção deste tipo de material.

Foram realizados testes em duas etapas, que permitiram à ArcelorMittal Tubarão aumentar a produtividade das máquinas de lingotamento contínuo e ampliar os limites de aceite dos aços baixo carbono microligados, por meio da elevação da velocidade de lingotamento e, consequentemente, da redução da largura mínima de placa permissível neste tipo de aço.

Além dos benefícios associados ao aumento de produtividade e de "market share", o aumento da velocidade de lingotamento dos aços baixo carbono microligados não impactou negativamente na qualidade interna das placas, uma vez que estes aços são menos susceptíveis a ocorrências de trincas por possuírem alta ductilidade a quente comparativamente aos aços peritéticos e médio carbono [3].

Em função dos bons resultados de qualidade interna neste material (família de aço 22), a ArcelorMittal Tubarão vem reduzindo significativamente o número de ensaios realizados de macro-ataque neste material nos últimos anos, alinhadas às diretrizes internas de redução de custo (2012: 578 amostras de macro ataque analisadas / 2013: 146 amostras).

A prática de elevação da velocidade de lingotamento no material baixo carbono também proporcionou uma melhoria na qualidade superficial das placas $\mathrm{e}$, consequentemente, acarretou em reduções dos índices de desclassificação e de descarte de bobinas por esfoliação na AM Tubarão.

\section{REFERENCIAS}

1 Hillenbrand HG, Kalwa C. Production and service behavior of high strength large diameter pipe. In: International Conference on Application and Evaluation of High Grade Linepipes in Hostile Environments. November 8-9, 2002; Yokohama, Japan. 2002.

2 Siciliano F. Materiais para gasodutos: aços de alta resistência para dutos de transporte de gás e petróleo - tendências atuais. Revista Metalurgia \& Materiais. 2008;64(588);208211.

3 Mintz B, Yue S, Jonas JJ. Relationship between hot ductility and cracking during the continuous casting of steel. In: Process Technology Conference Proceedings. 1995; Nashville, TN - USA. Warrandale: Iron and Steel Society; 1995. p.45-52.

* Contribuição técnica ao $45^{\circ}$ Seminário de Aciaria - Internacional, 25 a 28 de maio de 2014, 